\title{
Penerapan City Directory Dalam Membangun Identitas Kota Melalui Penyediaan Informasi Publik
}

\author{
Mulki Indana Zulfa ${ }^{1}$, Ari Fadli ${ }^{2}$, Eko Murdiyantoro A.M ${ }^{3}$ \\ ${ }^{1,2,3}$ Program Studi Teknik Elektro, Universitas Jenderal Soedirman \\ 1,2,3 Jln. Mayjen Sungkono Km.5 Blater Kec.Kalimanah Kab.Purbalingga 53371 \\ Email korespondensi : mulkiiz@unsoed.ac.id
}

Dikirim 19 Oktober 2016, Direvisi 09 November 2016, Diterima 19 Novemver 2016

\begin{abstract}
Abstrak - Kemampuan setiap kota dalam menarik investor dan wisatawan tersebut dapat dilihat dari bagaimana keseriusan pemerintah kota dalam membangun identitas kotanya. Salah satu hal yang dapat menjadikan sebuah kota memiliki identitas yang unik adalah kemampuannya menyediakan informasi publik yang benar dan lengkap mengenai hal-hal yang berkaitan dengan kota tersebut seperti fasilitas umum (fasum) dan fasilitas sosial (fasos). Salah satu konsep yang populer digunakan dalam menjawab tantangan tersebut adalah konsep city directory. City directory adalah aplikasi bentuk layanan berbasis lokasi untuk dapat memberikan informasi publik mengenai keberadaan fasum dan fasos dari sebuah kota. Penelitian ini dilakukan untuk membangun identitas kota purbalingga dengan menerapkan aplikasi city directory. Metode yang digunakan dalam penelitian ini adalah wawancara, analisis informasi, dan observasi langsung di lapangan. Kemudian untuk pendekatan pembangunan aplikasinya menggunakan waterfall method. Perancangan city directory yang dilakukan dalam penelitian ini merumuskan sistem manajemen direktori profil elemen-elemen kota seperti fasum, fasos, lokasi kantor pelayanan publik, dan tempat penting lainnya (place of interest).
\end{abstract}

Kata kunci - city directory, informasi publik, fasilitas umum, fasilitas sosial

Abstract - The ability of any city in attracting investors and tourists can be seen from how the city government's seriousness in establishing the identity of the city. One of the things that can make a city has a unique identity is its ability to provide public information that is correct and complete on matters related to the city as public facilities (public facilities) and social facilities (fasos). One popular concept used in answering these challenges is the concept of city directory. City directory is a location-based services application form to be able to provide public information about the presence of public facilities (public facilities) and social facilities (fasos) of a city. This study was conducted to establish the city's identity by applying purbalingga city directory applications. The method used in this study were interviews, analysis of information, and direct observation in the field. Then to approach application development using the waterfall method. Designing city directory that is performed in this study to formulate the profile directory management system elements of the city such as public facilities, social facilities, public service office locations, and other important places (place of interest).

Keywords - city directory, public information, public facilities, social facilities

\section{PENDAHULUAN}

Globalisasi semakin menguat seiring perkembangan transportasi dan komunikasi yang semakin cepat, mudah dan murah [1], menjadikan batasan wilayah bukan lagi sebagai hambatan dalam pergerakan. Kondisi tersebut mengantarkan kota-kota kepada sebuah kompetisi besar untuk dapat menarik investor, pengunjung, dan penduduk [2] yang dapat menjadi penggerak perkembangan kota. Salah satu yang dapat menarik perhatian tersebut adalah keberadaan fasos dan fasum seperti fasilitas pendidikan, kesehatan, perbelanjaan, transportasi, perbankan, peribadatan, rekreasi, olahraga, serta fasilitas dan tempat menarik lainnya. Keberadaan fasilitas tersebut harus didukung oleh penyediaan dan penyebaran informasi yang memadai karena sangat dibutuhkan oleh masyarakat yang tinggal di dalam kota maupun masyarakat dari luar kota yang sedang atau akan berkunjung. Pemerintah daerah mempunyai peran penting dalam mengembangkan, menyediakan, dan menyebarkan informasi publik ini kepada masyarakat. Pemerintah dapat memanfaatkan media non elektronik maupun elektronik dalam mencapai tujuan tersebut. Dishubkominfo Purbalingga adalah salah satu bagian dari pemerintah daerah Purbalingga yang mempunyai tugas untuk menyediakan informasi publik kepada masyarakat. Saat ini Dishubkominfo belum memiliki media yang secara khusus digunakan untuk menyediakan dan menyebarkan informasi publik terkait fasilitas umum dan sosial di kota Purbalingga. Penelitian ini dilakukan untuk membantu pihak Dishubkominfo dalam mencapai 
tujuan tersebut. Media ini penting untuk segera dikembangkan mengingat kota Purbalingga semakin berkembang dengan adanya kampus Teknik Universitas Jenderal Soedirman di kota ini. Selain itu penelitian ini akan membantu pemerintah daerah untuk menarik lebih banyak investor karena kota ini terkenal ada identitasnya sebagai sentra industri knalpot, bulu mata, dan wig yang sudah bertaraf Internasional [3].

Hasil penelitian ini akan menjadi rekomendasi bagi pemerintah kota Purbalingga khususnya Dishubkominfo dalam mengoptimalkan penyediaan dan penyebaran informasi publik. Beberapa masalah yang ada di kota Purbalingga yang berkaitan dengan masalah penyajian informasi publik adalah sebagai berikut.

a) Purbalingga mulai berkembang menjadi kota industri, pendidikan, dan tujuan wisata namun di kota ini belum memiliki pusat informasi yang terintegrasi untuk place of interest tersebut.

b) Fasilitas pusat media informasi yang dimiliki oleh pemerintah daerah purbalingga dirasa belum cukup untuk memenuhi kebutuhan informasi bagi para pendatang baru di kota ini.

c) Kebutuhan untuk menyediakan media alternatif sebagai pusat informasi daerah yang mudah diakses dan digunakan oleh masyarakat mengenai tempat/lokasi/kantor daerah setempat.

\section{METODOLOGI PENELITIAN}

Metode pengembangan perangkat lunak yang digunakan adalah waterfall. Metode ini merupakan model pengembangan perangkat lunak yang sistematis, paling handal dan paling lama digunakan [6]. Metode waterfall dipilih karena tujuan aplikasi city directory ini sudah sangat jelas yaitu membuat aplikasi berbasis web sebagai pusat informasi daerah tentang fasum dan fasos serta point of interest lainnya di kota Purbalingga. Adapun tahapan penelitian yang dilakukan dijelaskan sebagai berikut.

\section{A. Pengumpulan Data}

Metode ini dimulai dengan pengumpulan data untuk memenuhi kebutuhan user. Pengumpulan data ini dilakukan dengan menggunakan pendekatan penelitian kualitatif yaitu penelitian yang menghasilkan data deskriptif mengenai kata-kata lisan maupun tulisan [4]. Teknik pengumpulan data yang digunakan adalah wawancara. Tahap wawancara dilakukan terhadap penyedia dan pengguna informasi. Penyedia informasi yang diwawancarai adalah Kasi Sarana Komunikasi dan Diseminasi Informasi di dishubkominfo kabupaten Purbalingga sedangkan wawancara terhadap pengguna informasi ditujukan pada mahasiswa di lingkungan Fakultas Teknik
Universitas Jenderal Soedirman dengan jumlah responden 30 .

Selain wawancara, teknik pengumpulan data lainnya adalah melalui survei informasi publik yang dimiliki oleh pemerintah kabupaten Purbalingga, dimana yang menjadi target adalah website dishubkominfo.

\section{B. Analisis Sistem}

Hasil wawancara dari pihak penyedia informasi, menghasilkan kebutuhan aplikasi sistem city directory berbasis web yang dapat diakses dari internet.

\section{Pengembangan Perangkat Lunak}

Karena model aplikasi yang dipilih berbasis website maka dalam membangun perangkat lunaknya menggunakan bahasa pemrograman PHP dengan menggunakan framework codeigniter dengan engine database mysql.

\section{Pengujian}

Pengujian dilakukan terhadap server lokal (localhost) terlebih dahulu. Pertimbangan ini diambil untuk kemudahan proses pengujian sistem baik oleh penyedia informasi maupun oleh pengguna informasi city directory. Skema pengujian menggunakan blackbox yang berfokus pada keluaran hasil dari respon masukan dari sebuah kasus uji [7].

\section{E. Implementasi dan pemeliharaan}

Setelah tahap pengujuan selesai, sistem di upload melalui hosting dan domain profesional agar dapat mudah diakses oleh masyarakat.

\section{HASIL DAN PEMBAHASAN}

\section{A. Hasil Wawancara}

Tabel 1. Data Wawancara dari Responden

\begin{tabular}{ll}
\hline Responden & \multicolumn{1}{c}{ Keterangan } \\
\hline & Sumber : \\
& Mahasiswa teknik Unsoed \\
& Responden : \\
& 31 \\
& Waktu : \\
Pengguna & 19 s/d 30 september 2016 \\
informasi & Lokasi : \\
& Kampus teknik unsoed \\
& Kesimpulan : \\
& Mahasiswa teknik membutuhkan informasi \\
& fasilitas umum daerah di wilayah \\
& Purbalingga untuk menunjang kegiatannya. \\
& Sumber : \\
& Kasi Sarana Komunikasi dan Diseminasi \\
& Informasi Dishubkominfo Purbalingga \\
& Responden : \\
& 1 \\
& Waktu : \\
& Lokeptember 2016 \\
informasi & \\
&
\end{tabular}




\begin{tabular}{ll}
\hline Responden & \multicolumn{1}{c}{ Keterangan } \\
\hline & $\begin{array}{l}\text { Dishubkominfo Purbalingga } \\
\text { Kesimpulan : } \\
\text { Dishubkominfo membutuhkan media } \\
\text { alternatif sebagai pusat informasi daerah. }\end{array}$ \\
\end{tabular}

Pada Tabel 1 ditunjukkan hasil wawancara dengan responden. Hasil wawancara terhadap penyedia informasi maupun oleh pengguna informasi menyatakan bahwa implementasi aplikasi sistem city directory sangat diperlukan sebagai pusat informasi daerah yang dapat diakses oleh semua masyarakat dan memiliki kemampuan untuk menambah sumber informasinya dari para penggunanya.

\section{B. Arsitektur Sistem}

Sistem yang dibangun memanfaatkan google API untuk kepentingan fungsionalitas aplikasi sebagai penunjuk arah (rute) dari posisi user yang mengakses menuju lokasi tujuan yang diinginkan (place of interest). Aplikasi sistem city directory ini membutuhkan webserver dan database server. Kemudian Internet akan menjadi media penghubung kedua server tersebut dengan perangkat atau gadget yang digunakan oleh user untuk mengakses city directory ini.

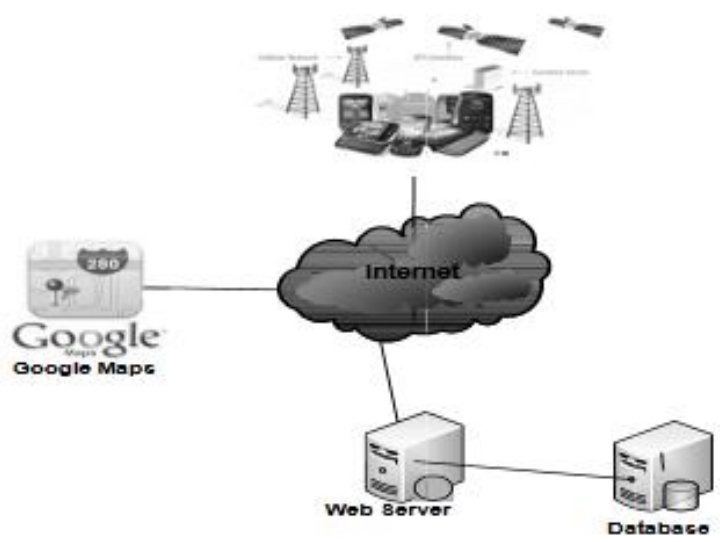

Gambar 1. Arsitektur Aplikasi Sistem City Directory

\section{Fungsionalitas Aplikasi}

Fungsionalitas aplikasi adalah fitur-fitur yang terdapat dalam sebuah aplikasi. Fitur yang didefinisikan akan diuji secara blackbox. Aplikasi city directory mempunyai beberapa fitur sebagai berikut.

a) Fitur pencarian, yaitu fitur yang digunakan untuk melakukan pencarian data fasos dan fasum yang ada di kota Purbalingga.

b) Fitur navigasi akan menampilkan rute menuju fasos dan fasum yang dipilih oleh user beserta perkiraan jarak dan waktu tempuhnya.

c) Fitur register dan login yaitu merupakan prosedur otentifikasi sistem user sebelum masuk ke dalam sistem city directory. d) Fitur tambah, edit, dan hapus Informasi yaitu fitur yang disediakan aplikasi untuk user yang berkeinginan mengelola data fasos dan fasum yang telah disimpan sebelumnya.

\section{Perancangan Database}

Adapun hasil dari penelitian yang dilakukan ini ialah berupa rancangan basis data. Rancangan basis data ini memiliki tabel-tabel yang telah terbentuk dari proses fase-fase perancangan konseptual, logical sampai fisikal. Perancangn basis data ini menghasilkan beberapa tabel basis data dan dimasukkan ke dalam database yang bernama citydir. Penerapan dari perancangan basis data dilakukan dengan menggunakan engine database MySQL. Dipilihnya MySQL karena kemudahan penggunaan dan instalasi [5]. Dari hasil analisis berdasarkan kegiatan observasi singkat yang dilakukan, maka dirancanglah 20 tabel seperti yang ditunjukkan pada Gambar 2.

\begin{tabular}{|c|c|c|c|c|c|c|c|c|c|c|}
\hline \multicolumn{2}{|c|}{ 呵 Structure } & Search & \multicolumn{2}{|c|}{ 畐Query } & Export & \multicolumn{2}{|c|}{ it 融mport } & \multicolumn{2}{|c|}{ Designer agerations } & Privileges \\
\hline & Table & & Action & & & Records ${ }^{1}$ & Type & Collation & Size & Overhead \\
\hline 0 & tb_bankname & 眯 舟 & 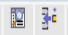 & III & $x$ & 10 & InnoDB & latin1_swedish_ci & $16.8 \mathrm{kiB}$ & \\
\hline 0 & tb_banktype & 艦 果 & 圆 率 & III & $x$ & 3 & InnoDB & latin1_swedish_ci & $16.8 \mathrm{KiB}$ & \\
\hline Q & tb_kamtibname & 唯 果 & 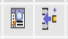 & III & $x$ & 2 & InnoDB & latin1_swedish_ci & $16.8 \mathrm{KiB}$ & \\
\hline 0 & tb_kamtibtype & 䨮 听 & 圆 弱 & III & $x$ & 4 & InnoDB & latin1_swedish_ci & $16.0 \mathrm{kiB}$ & \\
\hline 0 & tb_kantorname & 闑 听 & 圈 录 & III & $x$ & 6 & InnoDB & latin1_swedish_ci & $16.0 \mathrm{KiB}$ & . \\
\hline [ & tb_kantortype & 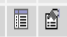 & 圈 亲 $\mathrm{t}$ & Iil & $x$ & 6 & InnoDB & latin1_swedish_ci & $16.0 \mathrm{KiB}$ & \\
\hline Q & th_kota & 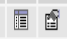 & 圆 弯 & iil & $x$ & 2 & $\ln n O D B$ & latin1_swedish_ci & $16 . \theta \mathrm{KiB}$ & \\
\hline 0 & tb_marketname & 䀠 舟 & 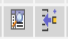 & III & $x$ & 3 & InnoDB & latin1_swedish_ci & $16 . \theta \mathrm{K} \mathrm{iB}$ & \\
\hline 0 & tb_markettype & 賏 & 圆 录 & III & $x$ & 3 & InnoDB & latin1_swedish_ci & $16 . \theta \mathrm{KiB}$ & \\
\hline 0 & tb_news & 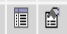 & 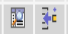 & III & $x$ & 3 & InnoDB & latin1_swedish_ci & $16 . \theta \mathrm{KiB}$ & \\
\hline ( & th_prov & 䀠 & 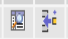 & Ii & $x$ & 3 & $\ln n O D B$ & latin1_swedish_ci & $16 . \theta \mathrm{KiB}$ & \\
\hline 0 & tb_pubtransname & 圈 噃 & 圆 率 $\mathrm{t}$ & III & $x$ & 2 & InnoDB & latin1_swedish_ci & $16 . \theta \mathrm{KiB}$ & \\
\hline 0 & tb_pubtranstype & 露 柦 & 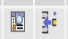 & III & $x$ & 4 & InnoDB & latin1_swedish_ci & $16 . \theta \mathrm{KiB}$ & - \\
\hline [ & tb__sname & 四 唕 & 国 亲 $\mathrm{t}$ & III & $x$ & 6 & InnoDB & latin1_swedish_ci & $16.8 \mathrm{KiB}$ & \\
\hline [ & tb_rstype & 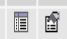 & 圆 新 & III & $x$ & 6 & InnoDB & latin1_swedish_ci & $16 . \theta \mathrm{KiB}$ & \\
\hline 0 & tb_sekolahname & 四 舟 & 圆 率 $\mathrm{i}$ & III & $x$ & 3 & $\ln n O D B$ & latin1_swedish_i & $16 . \theta \mathrm{kiB}$ & \\
\hline 0 & tb_sekolahtype & 哃 噃 & 圆 录 & III & $x$ & 13 & InnoDB & latin1_swedish_ci & $16 . \theta \mathrm{kiB}$ & \\
\hline [ & tb_user & 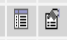 & 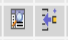 & III & $x$ & 1 & InnoDB & latin1_swedish_ci & $16 . \theta \mathrm{KiB}$ & \\
\hline [0 & tb_wisataname & 閳 㧹 & 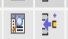 & II & $x$ & 4 & InnoDB & latin1_swedish_ci & $16 . \theta \mathrm{kiB}$ & - \\
\hline 4 & tb_wisatatype & 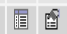 & 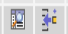 & III & $x$ & 4 & InnoDB & latin1__wedish_ci & $16.8 \mathrm{KiB}$ & . \\
\hline & 20 table(s) & & Sum & & & 88 & InnoDB & latin1_swedish_ci & $329.8 \mathrm{kiB}$ & $\theta B$ \\
\hline
\end{tabular}

Gambar 2. Implementasi Perancangan Database

\section{E. Arsitektur MVC Aplikasi}

Arsitektur MVC diimplementasikan dalam setiap modul aplikasi dalam sistem city directory ini. Setiap modul memiliki model, controller, dan beberapa view. Berikut ini akan dijelaskan implementasi arsitektur MVC pada city directory.

\section{F. Controller}

Controller akan mengendalikan alur program. Controller bekerja berdasarkan masukan user yang kemudian dikenal dengan nama task. Berdasarkan task tersebut maka controller akan mengambil data dari model dan mengirimkan data dari model tersebut ke view untuk ditampilkan pada browser. Berikut contoh controller yang yang berfungsi untuk proses otentifikasi pengguna ketika ingin login ke dalam sistem city directory. 


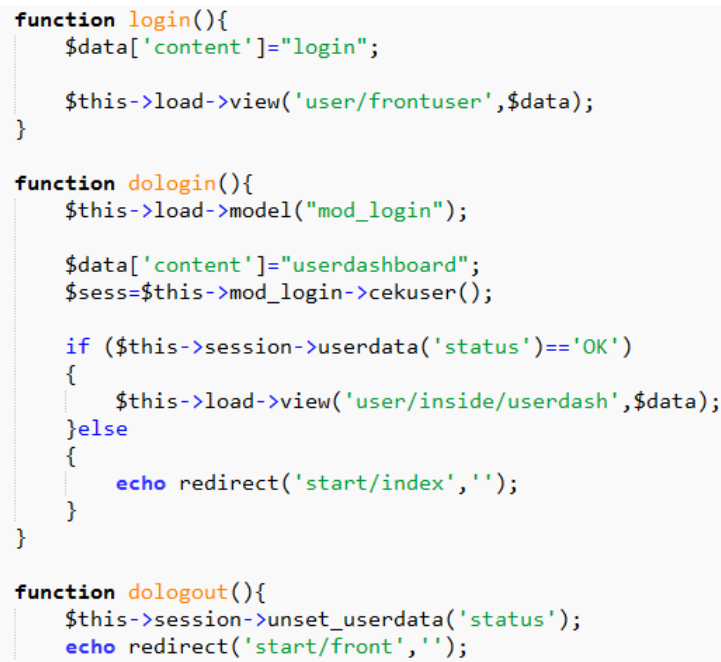

Gambar 3. Implementasi Controller Otentifikasi

Ada tiga fungsi dalam controller yang dibuat untuk keperluan proses otentifikasi.

a) Fungsi login

Fungsi ini digunakan untuk memanggil form login user.

b) Fungsi dologin

Fungsi ini akan melakukan pengecekan yang memanfaatkan data session, apakah user telah melewati serangkaian proses login sebelum memperoleh hak akses untuk masuk ke dalam sistem. Jika hasil pengecekan bernilai salah, maka user akan diarahkan ke dalam form login user.

c) Fungsi dologout

Fungsi ini digunakan untuk membawa user keluar dari aplikasi sekaligus menghapus data session user dari aplikasi.

\section{G. Model}

Model dibuat sebelum memulai memisahkan view antara bagian front-end yang digunakan untuk pengguna dan bagian back-end digunakan untuk administrator. Berikut contoh model yang yang berfungsi untuk proses otentifikasi pengguna ketika ingin login ke dalam sistem city directory. Cara kerja model ini diawali dengan pengecekan data login yang masuk, email dan password. Kemudian kedua data ini akan dicek ke dalam database untuk memastikan apakah benar pengguna yang login adalah user yang valid, telah melakukan proses register sebelumnya.

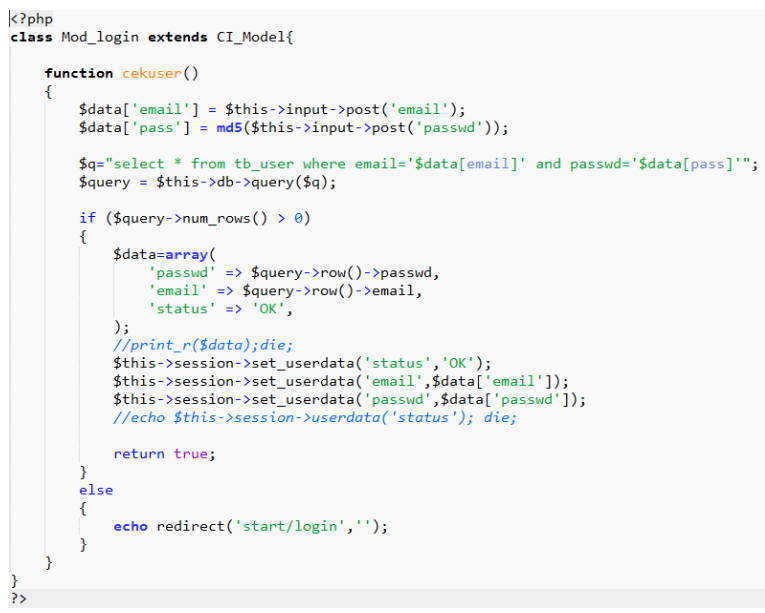

Gambar 4. Implementasi Model Otentifikasi Login

\section{H. View}

Aplikasi sistem city directory ini mempunyai 2 struktur view yang besar yaitu view untuk landing page dan view untuk halaman inti city directory. Halaman landing page khusus didesain menggunakan HTML5 yang memungkin tampilan website bersifat responsif.

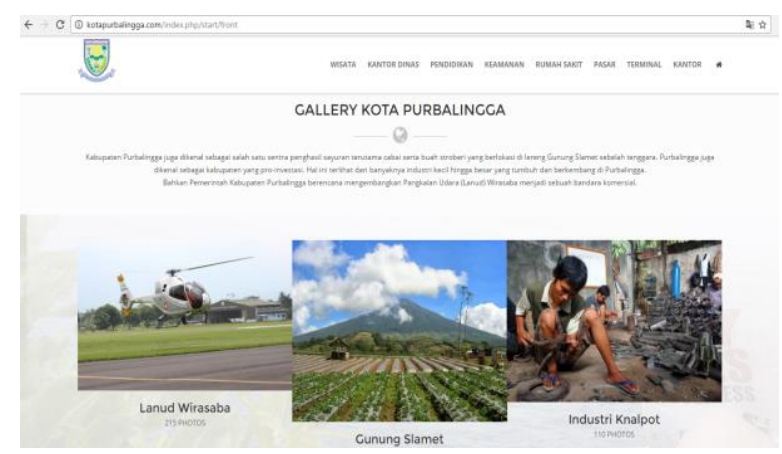

Gambar 5. Implementasi Landing Page

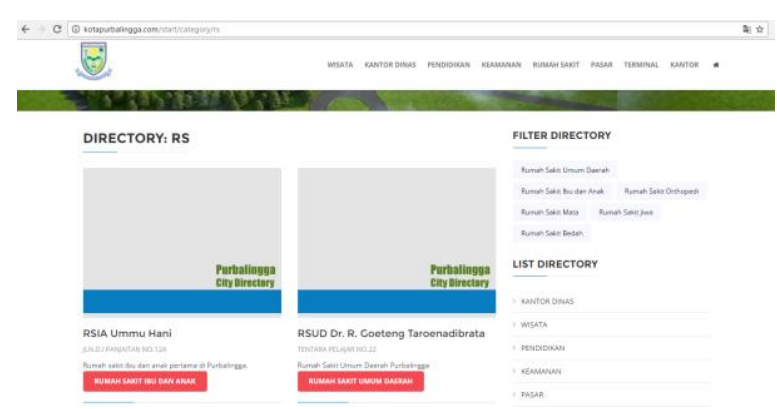

Gambar 6. Implementasi Halaman Inti City Directory

\section{Hasil Pengujian Sistem}

Selama ini pihak Dishubkominfo hanya menggunakan website official (http://dinhubkominfo.purbalinggakab.go.id/) dalam melakukan tugasnya sebagai penyedia dan penyebar informasi publik. 
ISSN : 2085-3688; e-ISSN : 2460-0997

Penerapan City Directory Dalam Membangun Identitas Kota Melalui Penyediaan Informasi Publik

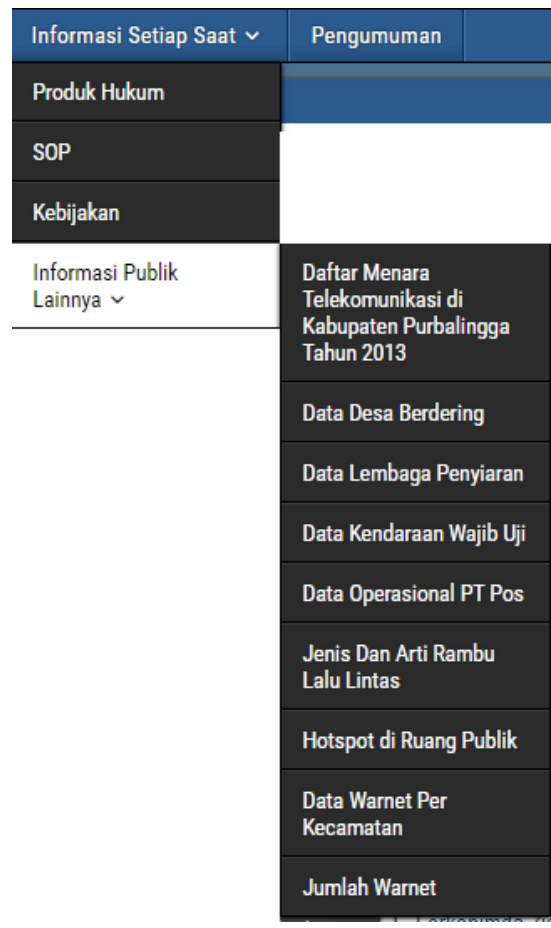

Gambar 7. Informasi Publik Pada Website Dishubkominfo

Daftar informasi publik yang disediakan oleh Dishubkominfo tidak menyertakan data fasum dan fasos yang ada. Dishubkominfo juga tidak menyediakan ruang khusus bagi masyarakat yang berkeinginan untuk menambah informasi publik yang ada.

Dengan diterapkannya aplikasi city directory, diharapkan masyarakat ikut berperan aktif dalam menambah informasi mengenai fasos, fasum, dan tempat menarik lain yang berada di lingkungan sekitarnya sehingga informasi ini akan sangat bermanfaat bagi masyarakat lain termasuk investor yang ingin berkunjung ke kota Purbalingga.

Pada Tabel 2 ditunjukkan hasil pengujian aplikasi dengan menggunakan metode blackbox.

Tabel 2. Hasil Pengujian City Directory

\begin{tabular}{|c|c|c|c|c|}
\hline No & Butir Uji & Tujuan & Jenis Uji & Hasil \\
\hline 1 & $\begin{array}{l}\text { Pencarian } \\
\text { data fasum } \\
\text { dan fasos }\end{array}$ & $\begin{array}{l}\text { Memeriksa } \\
\text { apakah hasil } \\
\text { pencarian sesuai } \\
\text { kriteria }\end{array}$ & $\begin{array}{l}\text { Sistem } \\
\text { Penguji : } \\
\text { Mahasiswa }\end{array}$ & Ok \\
\hline 2 & $\begin{array}{l}\text { Navigasi } \\
\text { menuju } \\
\text { fasum/fasos } \\
\text { yang dipilih }\end{array}$ & $\begin{array}{l}\text { Memeriksa } \\
\text { apakah rute yang } \\
\text { dihasilkan telah } \\
\text { sesuai dengan } \\
\text { kondisi } \\
\text { sebenarnya }\end{array}$ & $\begin{array}{l}\text { Penguji : } \\
\text { Mahasiswa }\end{array}$ & Ok \\
\hline 3 & $\begin{array}{l}\text { Fitur register } \\
\text { new user }\end{array}$ & $\begin{array}{l}\text { Memeriksa } \\
\text { apakah user baru } \\
\text { dapat mendaftar } \\
\text { untuk dapat } \\
\text { menggunakan } \\
\text { aplikasi }\end{array}$ & $\begin{array}{l}\text { Penguji : } \\
\text { Mahasiswa }\end{array}$ & $\mathrm{Ok}$ \\
\hline
\end{tabular}

\begin{tabular}{|c|c|c|c|c|}
\hline No & Butir Uji & Tujuan & Jenis Uji & Hasil \\
\hline 4 & $\begin{array}{l}\text { Fitur login } \\
\text { aplikasi }\end{array}$ & $\begin{array}{l}\text { Memeriksa } \\
\text { apakah valid user } \\
\text { dapat login ke } \\
\text { dalam aplikasi }\end{array}$ & $\begin{array}{l}\text { Penguji : } \\
\text { Mahasiswa } \\
\text { Staf Dinas }\end{array}$ & Ok \\
\hline 5 & $\begin{array}{l}\text { Fitur } \\
\text { penambahan } \\
\text { data } \\
\text { fasum/fasos } \\
\text { oleh user }\end{array}$ & $\begin{array}{l}\text { Memeriksa } \\
\text { apakah data } \\
\text { fasum/fasos yang } \\
\text { didaftarkan dapat } \\
\text { disimpan oleh } \\
\text { aplikasi }\end{array}$ & $\begin{array}{l}\text { Penguji : } \\
\text { Mahasiswa } \\
\text { Staf Dinas }\end{array}$ & Ok \\
\hline 6 & $\begin{array}{l}\text { Fitur } \\
\text { penghapusan }\end{array}$ & $\begin{array}{l}\text { Memeriksa } \\
\text { apakah data } \\
\text { fasum/fasos yang } \\
\text { didaftarkan dapat } \\
\text { dihapus dari } \\
\text { aplikasi }\end{array}$ & $\begin{array}{l}\text { Penguji : } \\
\text { Staf Dinas }\end{array}$ & Ok \\
\hline
\end{tabular}

Hasil pengujian menunjukkan semua fungsionalitas aplikasi yang telah didefinisikan sebelumnya dapat berjalan dengan baik.

\section{PENUTUP}

\section{A. Kesimpulan}

a) Dalam pengembangan sebuah kota khususnya mengenai pelayanan informasi publik, perlu dibangun satu sistem khusus yang dapat diakses oleh semua stakeholder yang terlibat untuk ikut berkolaborasi dalam mengumpulkan data yang valid mengenai keberadaan suatu tempat/bisnis/kegiatan (place of interest).

b) Purbalingga city directory dapat dijadikan solusi media alternatif bagi pemerintah dalam mengakomodasi keinginan masyarakat untuk memperoleh informasi yang lengkap mengenai fasum dan fasos.

c) Penerapan aplikasi city directory dapat membantu tugas Dishubkominfo dalam menyediakan dan menyebarkan informasi yang bermanfaat bagi masyarakat, khususnya informasi yang berkaitan dengan fasum, fasos, dan tempat menarik lainnya.

\section{B. Saran}

a) Sistem ini membutuhkan kerjasama dengan pelaku bisnis advertising agar makin banyak masyarakat yang mengetahui keberadaan sistem city directory ini.

b) Sistem ini dapat dikembangkan ke dalam versi smartphone agar segementasi pemakainya lebih luas. 


\section{DAFTAR PUSTAKA}

[1]. Avraham, Eli \& Ketter, E.2008. Media Strategies For Marketing Places In Crisis.Elsevier Inc.

[2]. Kavaratzis, M. 2008. From City Marketing to City branding; An Interdisciplinery Analysis with Reference to Amsterdam, Budapest and Athens. Groningen, the Netherlands.

[3]. Nugroho, A. C. 2010. Analisis Profil Industri Knalpot Purbalingga, Kabupaten Purbalingga. Skripsi Fakultas Ekonomi Universitas Diponegoro.
[4]. Sutinah, \& Suyanto, B.2005. Metode Pendekatan Sosial : Berbagai Alternatif Pendekatan. Jakarta : Kencana Prenada Media Group.

[5]. Vaswani, Vikram. 2010. MySQL Database Usage \& Administration. McGraw-Hill.

[6]. Pressman, Roger. 2012. Rekayasa Perangkat Lunak, Pendekatan Praktisi Edisi 7. Yogjakarta: Andi Publisher.

[7]. A.S Rosa dan Salahuddin M. 2011. Modul Pembelajaran Rekayasa Perangkat Lunak, Terstruktur dan Berorientasi Objek. Bandung: Modula. 